\section{Measuring Root Surface Area and Mean Root Diameter of Peach Seedlings by Digital Image Analysis}

\author{
M. Tagliavini', L.J. Veto, and N.E. Looney \\ Agriculture Canada Research Station, Summerland, BC VOH 1Z0, Canada
}

Additional index words. Prunus persica, growth regulators

\begin{abstract}
Using area profile integration software and an image processing system, we reliably estimated total root surface area of intact each [Prunus persica (L.) Batsch.] seedlings by 1) producing high-quality monochromatic video images under preset and constant conditions; 2) determining a threshold gray intensity value that differentiates the finest roots on the image; 3 ) producing a binary image where all pixels with gray values above the threshold are black; 4) determining the proportion of black pixels on the $480 \mathrm{x}$ 512-pixel matrix; and 5) multiplying this two-dimensional root surface value by $\pi$ to estimate total root surface area. Normalized intensity (an average intensity weighted according to the proportion of the binary image in each gray scale class) was calculated using software that superimposed the video image on the binary image and was used to estimate mean root diameter. Evidence of reliability and examples of the use of both estimates are provided.
\end{abstract}

Intact root systems are difficult to measure with a high degree of accuracy. The task is even harder if the aim is to make periodic measurements of root growth and root system development on the same plant. These difficulties probably account for our meager understanding of how root environment affects total root surface area and mean root diameter, which are physiologically important indicators of development. Total root surface area likely influences the kinetics of water and mineral uptake (Smika and Klute, 1982), and root diameter influences net ion influx into roots (Peterson and Barber, 1981).

The traditional methods for measuring root systems have been reviewed by Bohm (1979). Total root surface area can be determined from the sum of all root length and diameter measurements, by solution uptake methodology, and more recently, by digital image analysis. Mean root diameter can be calculated from surface area and root length (or root volume) by assuming that roots are cylindrical.

Digital image analysis has several advantages (Stutte, 1990), the most important being speed and accuracy. It has been used to estimate root surface area of corn (Zea mays L.) (Smika and Klute, 1982) and onion (Allium cepa L.) (Ottman and Timm, 1984) grown in soil or in nutrient solution, and the algorithm used to calculate the surface area of both groups has been refined by Yanuka and Elrick (1985). Recent developments in electronic hardware and software have greatly improved

Received for publication 23 Mar. 1992. Accepted for publication 13 June 1993. Summerland Research Station contribution 806. The cost of publishing this paper was defrayed in part by the payment of page charges. Under postal regulations, this paper therefore must be hereby marked advertisement solely to indicate this fact.

${ }^{1}$ To whom reprint requests should be addressed. Current address: Istituto di Coltivazioni Arboree, Univ. of Bologna, 40126 Bologna, Italy. subjected to a preset combination of transmitted and reflected light to eliminate shadows.
The camera lens, placed $94 \mathrm{~cm}$ above the root system, produced a $15 \times 14-\mathrm{cm}$ image that was digitized to512 $\times 480$ pixels with gray values ranging from 0 to 255 . These images were either processed immediately or stored for future analysis. All image processing involved the area profile integration software of the Tracer-Northem model 5502 advanced image processing system (Tracer-Northem, Middleton, Wis.).

Root surface area was estimated by 1) determining a gray-value threshold corresponding to the finest roots displayed on the video image; 2 ) producing a binary image (all roots are black, and the background-all pixels with gray values below the threshold-is white); 3) determining the total number of pixels occupied by roots; 4) determining the proportion of the total pixel matrix occupied by a root image and transforming this to a twodimensional root surface area; and 5) multiplying the two-dimensional root surface area by $\pi$ to obtain total root surface area (roots are assumed to be cylindrical.).

Estimating average root diameter. Video image analysis can be used to estimate average root diameter by assuming that thicker roots produce a darker gray level on the video image than thinner roots and that the entire video image of a root system is composed of pixels displaying up to 256 gray levels. The Tracer-Northem software, developed to analyze fiber thickness for the pulp and paper industry, was used to determine average root diameter. For this specific application, we processed composite samples of peach roots of known length and diameter (determined with an ocular micrometer) with the video image analysis procedure described earlier to determine root surface area. The black and white binary image (step 2) is then superimposed onto the original video image. The ratio between the digitized root image intensity and the binary root image area is the value referred to as "normalized intensity." The natural logarithm (in) of normalized intensity was used to estimate average root diameter using the equation $\mathrm{Y}=1063 \mathrm{X}^{-1.5341}$, where $\mathrm{Y}$ is the mean root diameter, and $\mathrm{X}$ is the normalized intensity. The coefficient of determination $\left(r^{2}\right)$ of 0.96

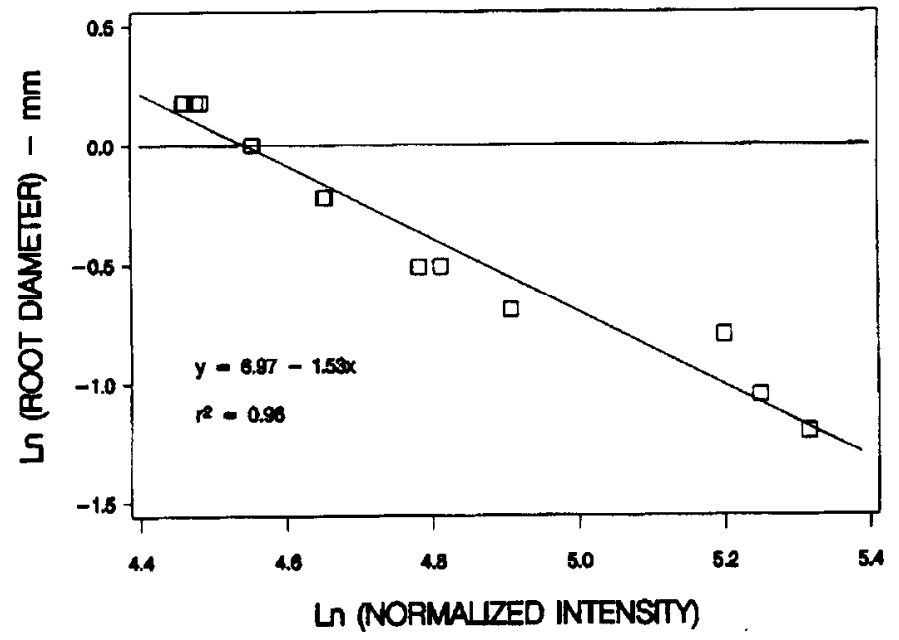

Fig. 1. Regression of natural logarithm (ln) of measured diameter (mm) vs. ln of normalized intensity. 


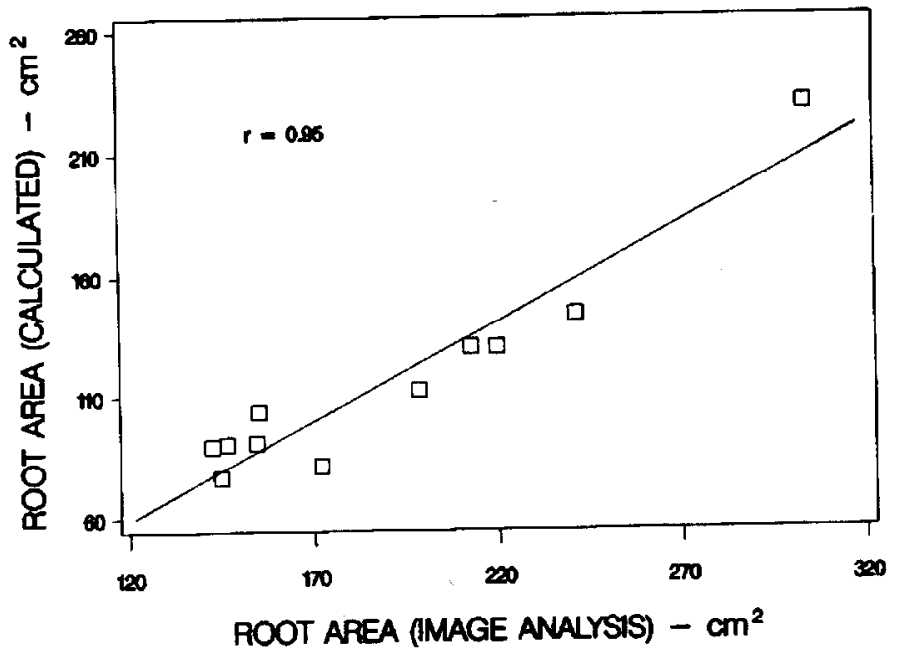

Fig. 2. Correlation between calculated root surface area and image analysis estimate of surface area of peach seedling root systems. indicates excellent ability to predict root diameter from normalized intensity. The standard error of the estimate indicated that a $95 \%$ confidence interval of $\pm 0.04 \mathrm{~mm}$ can be expected on the average root diameter estimation (Fig. 1).

Finally, to test the utility and reliability of both approaches to root system analysis, we processed whole peach seedling root systems using digital image analysis and then destructively examined each root system using other procedures. Total root length was determined using the line intersect method (Tennant, 1976) and the Comair Rootlength Scanner (Hawker de Haviland Victoria, Melbourne, Australia). Average diameter of a subsample of roots dispersed on a $1 \times 1-\mathrm{cm}$ grid was determined with an ocular micrometer. Root surface area was calculated as the product of root length $x$

Table 1. Comparison of manual and image analysis estimates of average root diameter of peach seedlings grown for 28 days in nutrient solutions varying in $P$ concentration.

\begin{tabular}{lcc}
\hline & \multicolumn{2}{c}{ Root diam estimate $(\mathrm{mm})$} \\
\cline { 2 - 3 } P concn $(\mathrm{mM})$ & Manual & Image analysis \\
\hline 0.05 & $0.62 \pm 0.16^{\mathrm{z}}$ & $0.61 \pm 0.06^{2}$ \\
0.5 & $0.59 \pm 0.09$ & $0.60 \pm 0.06$ \\
5.0 & $0.57 \pm 0.11$ & $0.56 \pm 0.01$ \\
$\mathrm{Cv}(\%)$ & 20 & 7 \\
\hline
\end{tabular}

${ }^{2}$ Average of four complete root systems $\pm \mathrm{sD}$.

average root diameter $\times \pi$.

Total root surface area as determined by image analysis proved to be highly correlated to calculated area (Fig. 2), although the slope was $<1(0.90)$. Thus, the image analysis procedure appears to overestimate slightly surface area relative to the calculated value. Similarly, we found the two sets of values for root diameter (Table 1) to be in close accord, with a smaller $\mathrm{cv}$ in the image analysis set.

We stress that, each time images are acquired, the investigator must use standardized instrument conditions (i.e., light intensity, type of illumination, lens opening, magnification, camera mode, working distance). The procedure for estimating mean root diameter requires using both transmitted and reflected light to obtain complete differentiation of root diameters in terms of pixel intensities. It is essential to use a new calibration and new equations when standard conditions change.

We also obtained very satisfactory results when we used the image analysis approach to nondestructively estimate root characteristics in two other experiments involving peach seedlings grown in nutrient solution. In the first (Tagliavini and Looney, 1991), 'Rutger's Red Lear peach seedlings were exposed to a rootzone temperature (RZT) of 10,16 , or $22 \mathrm{C}$ and were subjected to 0 or $2 \mathrm{mg}$ gibberellic acid $\left(\mathrm{GA}_{3}\right) /$ liter, 0 or $2 \mathrm{~g} \beta$ - [(4-chlorophenyl)meth-

Table 2. Effects of root-zone temperature $(T)$ and $P$ concentration on the image analysis estimates of root surface area and mean root diameter of 'Siberian C' peach seedlings grown in solution culture for 3 weeks.

\begin{tabular}{|c|c|c|c|c|c|c|c|}
\hline \multirow[b]{3}{*}{$P$ concn $(\mathrm{mM})$} & \multicolumn{3}{|c|}{ Root surface $\left(\mathrm{cm}^{2}\right)$} & \multirow[b]{3}{*}{ Significance } & \multirow{2}{*}{\multicolumn{2}{|c|}{$\frac{\text { Root diam }(\mathrm{mm})}{\mathrm{T}\left({ }^{\circ} \mathrm{C}\right)}$}} & \multirow[b]{3}{*}{ Significance } \\
\hline & & \multicolumn{2}{|c|}{$\mathrm{T}\left({ }^{\circ} \mathrm{C}\right)$} & & & & \\
\hline & & 16 & 24 & & 16 & 24 & \\
\hline$\overline{---}$ & --- & $98^{z}$ & $164^{2}$ & $* * *$ & --- & --- & \\
\hline 0.05 & $135^{y}$ & -- & --- & & 0.58 & 0.52 & NS \\
\hline 0.50 & $137^{y}$ & --- & --- & & 0.49 & 0.53 & NS \\
\hline 5.00 & $122^{y}$ & --. & --- & & 0.54 & 0.48 & ** \\
\hline Significance & NS & & & & NS & $\mathrm{Q}^{*}$ & \\
\hline $\mathbf{P} \times \mathbf{T}$ & & & & NS & & & \\
\hline
\end{tabular}

${ }^{2}$ Mean value across all $\mathbf{P}$ concentrations.

y Mean value across both root-zone temperatures.

ws, $; * * * * * N$ Nonsignificant or significant at $P \leq 0.05,0.01$, or 0.001 , respectively; $\mathrm{Q}=$ quadratic trend obtained by orthogonal contrast. yl] $-\alpha$ - (1,1-dimethyl)-1 $H$ - 1,2,4-triazole-1ethanol (paclobutrazol, PBZ)/liter, or a combination of these plant growth regulators in the nutrient solution. In a second experiment (Tagliavini et al., 1991), 'Siberian C' peach seedlings grown at an RZT of 16 or $24 \mathrm{C}$ received three levels of $\mathrm{P}(0.05,0.5$ and 5.0 $\mathrm{mM})$ in the nutrient solution. In both experiments, plants were transported intact to the image analysis facility, removed from the solution, and blotted dry; root images were acquired and stored in memory; and plants were placed back into the culture solution without creating any visible stress or noticeable effect on subsequent growth. The seedling roots were out of solution for $<2 \mathrm{~min}$.

With both experiments, the procedure detected significant effects of RZT on root-surface area (Table 2; Tagliavini and Looney, 1991). The elevated $P$ level reduced the mean root diameter of seedlings held at $24 \mathrm{C}$ (Table 2 ), and in the experiment involving plant growth regulation (Tagliavini and Looney, 1991), PBZ treatment led to a significant increase in mean root diameter $(1.13 \mathrm{~mm}$ across all RZTs vs. $0.94 \mathrm{~mm}$ for the control).

While our work to date has involved only peach seedlings and we have not determined the limits of seedling size or age, we are satisfied that these procedures can be used to reliably estimate root surface area and mean root diameter of root systems growing in solution culture. The method extends the usefulness of video imagery as a tool to improve our knowledge of root system development. Because this method is nondestructive, it should prove particularly useful in experiments studying the effects of root-zone temperature, substrate fertility, and plant-growth-regulating chemicals on the kinetics of root system development.

\section{Literature Cited}

Baxes, G.A. 1984. Digital image processing, a practical primer. Prentice Hall, Englewood Cliffs, N.J.

Bohm, W. 1979. Methods of studying root systems. Springer-Verlag, New York.

Green, W.B. 1989. Digital image processing: A systems approach. 2nd ed. Van Nostrand Reinhold, New York.

Ottman, M.J. and H. Timm. 1984. Measurements of viable plant roots with the image analyzing computer. Agron. J. 76:1018-1020.

Peterson, W.R. and S.A. Barber. 1981. Soybean root morphology and K uptake. Agron. J. 73:316-319.

Smika, D.E. and A. Klute. 1982. Surface area measurement of corn root systems. Agron. J. 74:10911093.

Stutte, G.W. 1990. Analysis of video images using an interactive image capture and analysis system. HortScience 25:695-697.

Tagliavini, M., E.J. Hogue, and G.H. Neilsen. 1991. Influence of phosphorus nutrition and root zone temperature on growth and mineral uptake of peach seedlings. J. Plant Nutr. 14:1267-1276.

Tagliavini, M. and N.E. Looney. 1991. Response of peach seedlings to root-zone temperature and root-applied growth regulators. HortScience 26:870-872

Tennant, D. 1976. A test of a modified line intersect method of estimating root length. J. Ecol. 63:9951001.

Yanuka, M. and D.E. Elrick. 1985. Applications of microcomputer-based image digitization in soil and crop sciences. Computers \& Electronics Agr. 1:5973. 